\title{
A produção do conhecimento em psicologia a partir das experiências de mulheres negras diaspóricas. Aspectos teórico-metodológicos
}

The production of knowledge in psychology from the experiences of diasporic black women. Theoretical-methodological aspects

Vivane Martins Cunha

Universidade Federal de Minas Gerais

Camila Rodrigues Francisco

Pontifícia Universidade Católica de São Paulo

Lisandra Espíndula Moreira

Universidade Federal de Minas Gerais

\section{Resumo}

Partindo das experiências de mulheres negras diaspóricas, problematizamos aspectos teóricometodológicos da produção do conhecimento científico na psicologia, com o intuito de enfrentar o racismo genderizado e o epistemicídio. Tomamos como base analítica os desafios vivenciados em duas pesquisas nas quais as experiências de mulheres negras diaspóricas foram centrais para a compreensão das dinâmicas de opressão. Insurgimos contra modelos teóricometodológicos pautados em uma racionalidade científica produtora de uma humanidade universalizante de matriz eurocêntrica, que se sustenta em noções colonizadas, excludentes e genocidas de produção de conhecimento. Compartilhamos, a partir do diálogo e da articulação de vozes negras e decoloniais, outros caminhos possíveis para a práxis científica psi em que corpos, vozes e escritas marginalizadas atuam como faróis a conduzir quizumbas e caos fomentadores de criticidade, criatividade e novas insurgências teórico-metodológicos, visando transformar a ciência de modo a destruir seus muros e construir novas pontes.

Palavras-chave: Mulheres negras; Epistemologia; Metodologia; Psicologia Social

\begin{abstract}
Based on the experiences of black women, we problematize theoretical and methodological aspects of the production of scientific knowledge in psychology, in order to face gendered racism and epistemicide. We take as an analytical basis two researches in which the experiences of black diasporic women are central to understanding the dynamics of oppression. We argue against theoretical and methodological models based on a scientific rationality that produces a universalizing humanity with a Eurocentric matrix, which is based on colonized, exclusionary and genocidal notions. knowledge production. We share with the dialogue and articulation of black and decolonial voices, other possible paths for psi scientific praxis in which marginalized bodies, voices and writings act as beacons to lead quizumbas and chaos that foster criticality, creativity and new theoretical and methodological insurgencies, aiming at transform science in order to destroy its walls and build new bridges.
\end{abstract}

Keywords: Black women; Epistemology; Methodology; Social Psychology 


\section{CANTOS DE MULHERES-PÁSSAROS}

Um pássaro aprisionado na imagem fantasiada pelo outro, que o engaiola em tortuosas grades da intolerância e do ódio. Um pássaro que desafia o silêncio e canta sobre a liberdade, a despeito das suas asas feridas e dos seus pés amarrados. Um pássaro que, mesmo com seu gorjeio sufocado e seu corpo condenado ao exílio (ou à morte), levanta-se e continua a cantar. A partir da leitura de Maya Angelou (1969/2018, 1978/2020), escritora e poetisa estadunidense, compreendemos que a nossa escrita tem o intuito de compartilhar cantos de mulheres-pássaros. Cantos de vida e de morte, de alegria, afeto, revolta, esperança, tristeza, silêncio, violência, sofrimento, raiva, de luto e luta. São cantos das águas que carregam vestígios de memórias ancestrais, de outras vivências afetivas, sociais, culturais e políticas.

Consideramos, então, que a leitura dos escritos de Angelou suscita a efígie de mulheres-pássaros, pois em sua escrita há um contínuo levantar da mulher negra que, mesmo em terrenos hostis a sua existência, tal como um pássaro engaiolado, segue a cantar por liberdade. Na poesia "Ainda assim eu me levanto" (1978/2020), a autora escreve: "Você pode me riscar da História com mentiras lançadas ao ar. Pode me jogar contra o chão de terra, mas ainda assim, como a poeira, eu vou me levantar". Em "Quarto de despejo" (1960), Carolina Maria de Jesus, escritora e poetisa brasileira, escrevia: "Todas as manhãs eu canto. Sou como as aves que cantam apenas ao amanhecer" (p. 23). Uma vida de catadora, lutando diariamente contra a fome: " $O$ mundo das aves deve ser melhor do que dos favelados, que deitam e não dormem porque deitam-se sem comer" (Jesus, 1960, p. 30).

Luísa, Carolina, Maria, Tereza, Esperança ${ }^{1}$ são mulheres negras brasileiras, moradoras de periferias e favelas em diferentes municípios do estado de Minas Gerais, que tiveram seus filhos assassinados em decorrência de intervenção policial. Elas nos contam cenas das histórias de seus filhos que partiram, histórias que se intercruzavam com as delas, de modo que se entrelaçavam a construir novos arranjos que compunham seus enredos de vida. A ausência dos filhos significa para essas mulheres a morte em vida; parte de seus cantos de mulherespássaros deixou de ecoar. Entretanto, essas mulheres também partilham o reconstruir de seus voos, driblando a dor e a saudade e lidando com a raiva diante da injustiça. Elas seguem a reinventar o cotidiano, ao mesmo passo em que se reinventam, e passam a construir pequenos/grandes novos futuros (Cunha,

\footnotetext{
${ }^{1}$ Nomes fictícios das mães que foram interlocutoras da pesquisa "Vestígios de histórias silenciadas: Vozes de mães sobre o genocídio negro", realizada pela primeira autora, sob a orientação da terceira autora deste texto. Também tivemos como interlocutora dessa pesquisa uma mãe branca, Sílvia.
} 
2019). Como retumba a voz da militante brasileira Débora Silva, fundadora do movimento Mães de Maio: "Eles que nos matam-vivas todos os dias, e fazem questão de não nos escutar. Mas nós insistimos em gritar! $E$ insistimos em sorrir também! Não vão tirar isso da gente!” (Mães de Maio, 2011, p. 15).

Embora as mulheres-pássaros tenham sido forjadas em campos áridos aos seus cantos de liberdade, após travessias forçadas pelo Atlântico devido à colonização das Américas, e submetidas a longos períodos de violências coloniais e póscoloniais, que coíbem o ecoar de suas vozes, seus cantos não sucumbiram ao deserto, e seus corpos continuam a resistir ao genocídio negro. Essa é a estética das vivências diaspóricas que reivindicamos neste artigo ${ }^{3}$. Como canta Luedji Luna, compositora e cantora brasileira: "Para que te quero, asas? Se eu tenho ventania dentro" (2017). Assim, mesmo com asas quebradas, as mulherespássaros reerguem-se, e suas vozes ainda encontram a potência necessária para estilhaçar as máscaras do silenciamento com o vento de dentro (Evaristo, 2009/2017; Kilomba, 2008/2019). "Mulher do fim do mundo. Eu sou e vou até o fim cantar”, canta Elza Soares (2015), outra compositora e intérprete brasileira.

Judie e Michou 4 , mulheres negras haitianas e estudantes universitárias, evidenciam, por meio de seus relatos, a capilarização do racismo no tecido social brasileiro, herança do colonialismo, que mantém a inferiorização de vivências diaspóricas. Ao compartilhar suas histórias, elas sublinham vivências de racismo

2 Esse movimento de mães surgiu após os assassinatos de aproximadamente 493 pessoas, que constam como mortas ou desaparecidas, no estado de São Paulo, como retaliação por parte dos agentes públicos de segurança e de grupos de extermínio ligados ao Estado, que declararam guerra aos moradores de favelas e periferias de São Paulo devido ao confronto da polícia com o Primeiro Comando da Capital (PCCS) - organização criminosa que atua dentro dos presídios brasileiros (Mães de Maio, 2011).

3 Se a palavra diáspora designa expulsão ou deslocamento forçado de um território, a rigor, uma nação, entendemos a diáspora africana/negra como o processo de dispersão dos então povos africanos, de diferentes etnias e territórios, para as Américas, amplamente ancorada na escravização (tráfico de pessoas), mas também anterior e a despeito dela. Para além dos aprofundamentos que o termo diáspora evoca quando interpela os territórios - as noções de nacionalidade e identidade nacional e outros aspectos (Francisco, 2019) - temos ainda outros usos possíveis do termo (Edwards, 2017). A estética das vivências e das experiências diaspóricas negras que erigimos ao longo do texto tem justamente como horizonte a travessia do Atlântico, a recriação das violências coloniais nos territórios ocupados a partir dessa travessia, e a reivindicação de existência e resistência secular que emerge do mesmo processo.

${ }^{4} \mathrm{Na}$ pesquisa de mestrado "Trajetórias em diáspora: A experiência de universitárias haitianas de Belo Horizonte", realizada pela segunda autora deste texto, sob a orientação da Prof. Dra. Claudia Mayorga, consideramos como interlocutora(e)s toda(o)s a(o)s participantes do estudo, que se identificaram como preferiram. Sendo assim, alguns nomes são fictícios, outros não. Judie e Michou foram as interlocutoras principais, cujos relatos das entrevistas semiestruturadas aparecem ao longo dos capítulos (Francisco, 2019). 
na cotidianidade das relações sociais e institucionais no Brasil. A saída da casa - lar-comunidade-país de origem - lança-as à diáspora (d)na diáspora. Tal deslocamento territorial é vivenciado subjetivamente com muitas ambivalências. Por um lado, o acesso aos estudos representa a possibilidade de mobilidade social dessas mulheres, significando, também, uma aposta na abertura de novas rotas para outros familiares. Por outro, essas estudantes, por carregarem em seus corpos a cor da noite (Mbembe, 2013/2018) e a nacionalidade haitiana, ambas consideradas abjetas devido às suas raízes negras, deparam-se com o passado colonial presentificado nas relações cotidianas, que as engaiolam na imagem de estrangeiras indesejáveis.

Vivências e sentimentos ambivalentes também são abordados na autobiografia de Angelou, "Eu sei porque o pássaro canta na gaiola" (1969/2018). Ao compartilhar lembranças de sua infância e juventude, a autora transmite com sensibilidade as diversas formas de violência, estruturadas principalmente pelo racismo e pelo patriarcado. Angelou e sua família produziram formas de resistência cotidianas, seja pelas partidas e as chegadas nas casas de familiares, a cumplicidade do olhar ou do silêncio, um gesto de cuidado ou uma palavra de afeto, seja por jogar sagazmente com o próprio sistema de opressão, de modo a subvertê-lo ou, até mesmo, reproduzi-lo, em certa medida, por meio de atos de violência. É por meio da escrita de um cotidiano de outrora, não apagado, tampouco esquecido, que Angelou ecoa a sua voz, a sua história. A experiência de Angelou como uma mulher negra diaspórica nos fornece elementos para compreender o quanto de dor e de luta pela vida constitui as experiências de mulheres negras em diáspora.

$\mathrm{Na}$ escrita de Audre Lorde, outra escritora estadunidense, encontramos pistas sobre os mecanismos constitutivos da subjetividade "engaiolada" que convocam a reflexões permanentes sobre si como a Outra. "É mais fácil lidar com as manifestações externas do racismo e do machismo do que lidar com as consequências dessas distorções internalizadas na consciência que temos de nós mesmas e de outras" (Lorde, 1984/2020, p. 185). Como diz Jarid Arraes (2018), escritora, poetisa e cordelista brasileira: "Se eu fosse assim amável, amar a mim mesma seria fácil. Se eu fosse assim, que nem você, toda amor, toda feita de nuvens, maciez, pele bege, toda feita de ossos discretos, mas presentes... se eu fosse menos eu, se fosse amável, qualquer um, até eu, me amaria" (pp. 114-115).

Essas escritoras rompem com a romantização em torno de suas histórias e a naturalização do sofrimento negro, que não está apenas no passado, mas na atualização cotidiana sustentada pela desigualdade. "E, apesar de minha fala hoje desnudar-se no cálido e esperançoso sol de terras brasis, onde nasci, o gesto de 
meu corpo-escrita levanta em suas lembranças esmaecidas imagens de um útero primeiro", aponta Conceição Evaristo (2009/2017, p. 106), romancista, contista e poetisa brasileira. A vivência diaspórica nos remete a essas recordações revividas e atravessadas pela sociedade sedimentada no racismo e no patriarcado, retirando suas experiências de um cotidiano circunscrito à esfera íntima e individual e situando-as em contextos sociais e políticos. Assim, promovemos o encontro de vozes plurais, em que as escritas de Maya Angelou e Audre Lorde, as escritas de autoras brasileiras como Conceição Evaristo, Jarid Arraes, Carolina Maria de Jesus, e os cantos de Elza Soares e Luedji Luna se entrelaçam a apresentar notas de cantos de mulheres-pássaros. Desse modo, tomamos as marcas que encontramos nas escritas e nos cantos dessas mulheres negras como vestígios para a pesquisa com outras mulheres, mediando/localizando/refletindo sobre nossa própria voz e escrita.

Este artigo parte da multiplicidade de experiências de mulheres negras diaspóricas para problematizar a produção de conhecimento sobre a realidade social brasileira, tensionando perspectivas teórico-metodológicas relevantes para o enfrentamento do racismo genderizado (Kilomba, 2008/2019) e do epistemicídio (Carneiro, 2005) no campo da psicologia. É importante destacar que a experiência tem sido um conceito fundamental para o avanço e o acúmulo de produção de conhecimento no campo de estudos feministas, permitindo a significação da vivência de mulheres em sua ampla diversidade. Aqui, tomamos como referência o entendimento da filósofa e antropóloga brasileira Lélia Gonzalez (1984/2020, p. 140): "quando falo de experiência, me refiro a um processo difícil de aprendizado na busca de minha identidade como mulher negra, dentro de uma sociedade que me oprime e discrimina precisamente por causa disso".

Desse modo, colocamos em diálogo duas pesquisas, realizadas no âmbito da psicologia social, que analisam as experiências de mulheres negras, interseccionando-as com as categorias de gênero, classe, raça e nacionalidade para compreender as consequências desse amálgama de opressões nas experiências diaspóricas no Brasil. A pesquisa que traz as histórias de Luísa, Carolina, Maria, Tereza e Esperança teve como objetivo analisar o genocídio negro a partir da experiência de mulheres que perderam seus filhos em decorrência da violência policial. Para chegar até essas mães, foram construídas pontes com lideranças e referências comunitárias que representaram um caminho importante na constituição de encontros acolhedores e seguros a essas mulheres. Tal como foi relevante dialogar com Elizete, fundadora do grupo "Mães que choram, pais que abraçam" (BH/MG), para sedimentar os passos ético-metodológicos e epistemológicos antes da entrada no campo de pesquisa. Antes de chegar às estudantes 
haitianas Judie e Michou, os relatos de estudantes de outros países também foram trazidos, articulando reflexões em torno do racismo brasileiro na particularidade da experiência estrangeira. Além da categoria raça, também emergiram as particularidades e as posicionalidades das categorias gênero e nacionalidade, ao olhar para o Haiti e para as mulheres com centralidade. A partir do diálogo com intelectuais, pesquisadora(e)s e ativistas negra(o)s, principalmente do campo de estudos da diáspora africana/negra, ambas pesquisas apontam análises sobre as várias dimensões do genocídio do negro brasileiro na contemporaneidade.

Para tanto, as vozes de Elizete, fundadora do grupo "Mães que choram, pais que abraçam” (BH/MG), Luísa, Carolina, Maria, Tereza, Esperança, encontram com as de Judie e Michou e passam a ser os fios condutores de nossas discussões e reflexões. Compartilhamos os caminhos que escolhemos percorrer em nossas pesquisas, assim como perguntas e incômodos que daí decorrem, buscando traçar rotas insurgentes, ou seja, meios de transgredir um estado de coisas naturalizado ou colocado como hegemônico (Francisco e Mayorga, 2020) pelo saber científico, que ainda falha em registrar os movimentos (ou cantos) da vida em sua polifonia de vozes.

\section{INSURGÊNCIAS TEÓRICO-METODOLÓGICAS PARA VOZES QUASE INAUDÍVEIS}

Todas as manhãs junto ao nascente dia

ouço a minha voz-banzo, âncora dos navios de nossa memória.

E acredito, acredito sim que os nossos sonhos protegidos

pelos lençóis da noite

ao se abrirem um a um

no varal de um novo tempo

escorrem as nossas lágrimas

fertilizando toda a terra

onde negras sementes resistem

reamanhecendo esperanças em nós.

(Evaristo, 2009/2017, p. 13)

Como produzir, escutar, registrar e analisar as histórias dessas mulheres em pesquisas? De que forma romper com a posição de objeto à qual, por muito tempo, foram relegadas as vozes subalternas? Tomando a imagem do pássaro engaiolado de Angelou como referência, seria a pesquisa apenas espectadora de um canto da resistência, capturado por entre as grades do racismo? Do ponto de vista do registro de vozes de mulheres negras, a imagem do pássaro na gaiola interpela-nos de modo muito intenso. Seriam as pesquisas capazes de 
romper algumas dessas gaiolas, ou elas apenas capturam o canto, sem que o pássaro possa voar?

A travessia do Atlântico impôs às mulheres negras outras travessias de sofrimentos, lutas, silêncio e resistências. Compartilhamos aqui algumas dessas travessias, cientes de que "não é suficiente se posicionar na margem oposta do rio, gritando perguntas, desafiando convenções patriarcais, brancas" (Anzaldúa, 1987/2005, p. 705). Assumimos o compromisso ético-político-científico de não paralisar na margem oposta do rio (ou do oceano), mas, sim, de construir pontes com mulheres negras; reconhecendo a diferença existente entre nós, porém nos conectando a partir e para além das diferenças. Como nos ensina Lorde (1984/2020, p. 164), “a força das mulheres está em reconhecer as diferenças entre nós como algo produtivo e em defender sem culpa as distorções que herdamos, mas que agora são nossas e cabe a nós alterar".

Para construir pontes, é preciso descolonizar a produção do conhecimento. Não é uma tarefa simples e exige, como propõe a psicóloga brasileira Érika Oliveira (2020a), um comprometimento ético-político de criação de fraturas em uma ciência moderna, imbuída de cosmovisões fossilizadas, que historicamente se configurou como monopólio de saber e poder de grupos de descendentes de homens brancos colonizadores, que expandiram seus meios de dominação também ao campo científico. Em nossas pesquisas, para escutarmos as vozes de mulheres negras, ou o canto das mulheres-pássaros, jogamos fora "a abstração e o aprendizado acadêmico, as regras, o mapa e o compasso" (Anzaldúa, $1981 / 2000$, p. 235) que escondem na sua racionalidade moderna ocidental premissas de neutralidade e objetividade, pressupostos desumanizadores, principalmente quando corpos negros são colocados no lugar de objeto de estudo.

Nesse processo de descolonização, tomamos vozes e escritas como ferramentas de poder, que quando retomadas por sujeitas que delas foram destituídas, “numa história de silêncio imposto" (Kilomba, 2008/2019, p. 27), alcançam um nível perigoso e interessante. Colocando em questão as máscaras de silenciamento, a psicóloga e artista interdisciplinar portuguesa Grada Kilomba (2008/2019) expõe a história que tortura vozes, rompe línguas, impõe idiomas e impede a entrada e a permanência em lugares para que se possa falar com a própria voz. Dito de outro modo, o racismo genderizado (Kilomba, 2008/2019) marca violentamente as experiências de mulheres negras, e resgatar suas falas significa acionar histórias traumáticas, que são passadas de geração a geração. Tarefa nada simples, mas "quem disse que seria simples? Há tantas raízes na árvore da raiva que às vezes os galhos partem antes de brotar” (Lorde, 2020, pos. 1012p). 
Para pensar aspectos teórico-metodológicos das pesquisas com vozes de mulheres negras como foco deste artigo, priorizamos dialogar com a escrita de outras mulheres negras. Pensando nas histórias dessas mulheres-pássaros, possuímos ferramentas acuradas o suficiente para essa escuta? A partir de quais aspectos as tecnologias científicas hegemônicas não se mostram eficazes? A antropóloga brasileira Fátima Lima (2020), ancorada nas inquietações do psiquiatra martinicano Frantz Fanon, assinala "a insuficiência das explicações centradas em matrizes que têm na hegemonia branca sua referência para pensar a subjetividade e os processos subjetivos" (p. 83). Desse modo, buscamos pensar em metodologias insurgentes, vestígios de passos que vêm de longe e nos inspiram a estratégias de pesquisa cuidadosas e escutas acuradas capazes de amplificar essas vozes. "Desempalidecer epistemes", como propõe Oliveira (2020b), como exercício de reparação do mal causado pelo racismo, que posicionou o branco como voz privilegiada para narrar a realidade social e o universo acadêmico.

A ausência dessas reflexões em teorias clássicas da ciência psicológica evidencia o apagamento epistemológico, ou epistemicídio, como alerta a filósofa e escritora brasileira Sueli Carneiro (2005). Essa autora compreende o epistemicídio como uma forma de sequestro manifestada "pela negação da racionalidade do Outro ou pela assimilação cultural que em outros casos the é imposta" (p. 97). Assim, sujeita(o)s racializada(o)s são tida(o)s como inferiorizada(o)s intelectualmente, e suas produções epistemológicas são deslegitimadas e apagadas. Seguimos os passos de Carneiro (2005), que enfrenta o epistemicídio visibilizando resistências negras que se encarnam em suas múltiplas vozes e existências, dentro ou fora da academia, de modo a produzir rupturas nos dispositivos racializados de saber-poder. Assim, investimos em diálogos com teorias e perspectivas científicas não hegemônicas, especialmente tomando a psicologia social como nosso principal referencial teórico, e nos aproximamos da antropologia e do construcionismo social como eixos de análise, assim como autora(e)s latino-americana(o)s, haitiana(o)s e africana(o)s. Além disso, buscamos potencializar e visibilizar a contribuição de teóricas que às vezes encontram vazão em caminhos diferentes da academia, mas que circulam de maneira ampliada em escritas poéticas, biográficas, literárias, entre outras expressões culturais, tal como a música, o que pode ser considerado um conhecimento subjugado.

A supressão das ideias das mulheres negras em instituições sociais controladas por homens brancos levou as afro-americanas a usarem a música, a literatura, as conversas cotidianas e o comportamento cotidiano como dimensões importantes para a construção da consciência feminista negra. (Collins, 1990/2019, p. 402) 
Analisando o pensamento feminista negro estadunidense, a socióloga estadunidense Patrícia Hill Collins (1990/2019) ressalta características como a interconexão entre produção acadêmica e ativismo, destacando que as intelectuais negras são um grupo altamente diversificado, não abarcando apenas aquelas que são reconhecidas pela academia. Além disso, na busca da própria voz, individual e coletiva, Collins (1990/2019) indica a necessidade que mulheres negras tiveram de estabelecer lugares seguros para se expressar, analisando especificamente três espaços: a relação das mulheres negras umas com as outras, a música afro-americana e a escrita.

Carolina Maria de Jesus também tinha mãos que escreviam a caligrafia da resistência. "Aqui na favela quase todos lutam com dificuldades para viver. Mas quem manifesta o que sofre é só eu. E faço isso em prol dos outros" (Jesus, 1960, p. 32). A escrita como registro e descolonização, "ao reinventar a si mesma, nomeia uma realidade que fora nomeada erroneamente ou sequer foi nomeada" (Kilomba, 2008/2019, p. 28). As psicólogas brasileiras Rayanne Amorim e Érika Oliveira (2020) analisam a escrita de Carolina como escrita decolonial e feminista, mas que não obteve na crítica canônica brasileira da época o devido reconhecimento literário, sendo considerada apenas no seu valor descritivo e documental. Uma escrita perigosa exatamente por "emergir de um contexto de extrema violência, por representar um grupo que é silenciado no discurso, além de promover poderosas denúncias sociais e elaborar um texto que serve como instrumento político de resistência e visibilidade" (Amorim e Oliveira, 2020, p. 170).

Dessa forma, buscamos ampliar nossa roda de referências com outras vozes e escritas, que não apenas fornecem ferramentas metodológicas, mas também sensibilizam o olhar e a escuta. Elizete Marques, mulher negra brasileira e pastora evangélica, fundou o grupo "Mães que choram, pais que abraçam" após o assassinato do seu filho em 2012. As conversas com Elizete, antes da entrada no campo, foram fundamentais para a construção ética, política e epistemológica da pesquisa, algo não encontrado em manuais metodológicos. Há um amplo conhecimento na experiência de Elizete junto a outras mulheres que partilham seus sofrimentos e também constroem abrigos de cuidado e fortalecimento umas das outras. As falas de Elizete aguçaram a nossa escuta e despertaram sensibilidades, geralmente lidas pela objetividade científica como contaminação e/ou vieses de pesquisa. Assim, em consonância com os estudos feministas e decoloniais, apostamos na potencialidade da troca, da escuta e do cuidado, da conexão e não do distanciamento como fonte de conhecimento científico situado e responsável, dialogando especialmente com intelectuais negras, tais como Anzaldúa, Collins, Lorde, hooks, entre outra(o)s. Além disso, é importan- 
te destacar que o conhecimento transmitido oralmente por mulheres negras é de sabedoria ancestral e de resistência histórica, devendo ser resgatado, haja vista que é desvalorizado frente a uma ciência letrada pela língua do colonizador.

De forma semelhante, foram estudantes negra(o)s de diferentes nacionalidades que contribuíram com os contornos da pesquisa sobre a diáspora estudantil. "Qual a sua opinião acerca de estudos que abordam a experiência de estudantes estrangeiras negras?” (Entrada de diário de campo, junho, 2019) foi a pergunta respondida por Michou e Stephane, a(o)s primeira(o)s estudantes contatada(o)s durante o percurso de construção do projeto de pesquisa; a pergunta foi estendida a um amigo da Costa do Marfim e outro amigo haitiano. As respostas a essa indagação deram o tom da pesquisa com mulheres haitianas. Essa espécie de pré-campo e as demais conversas que ocorreram ao longo da investigação foram aportes reflexivos sobre os rumos do estudo, bem como os cuidados que deveriam ser tomados.

Esses diálogos estabelecidos antes da entrada efetiva nos referidos campos de pesquisa foram importantes sinalizadores de cuidados ético-epistemológicos, além de apontar pistas metodológicas sobre a complexidade de se inserir em campos de pesquisa constituídos por sujeitas que carregam marcas de violências diversas em seus corpos e subjetividades. "Quanto dessa verdade eu posso suportar ver e ainda viver sem me cegar? Quanto dessa dor eu posso usar?" (Lorde, 2020, pos.2433). A tarefa de escutar a história dessas mulheres, provocar a emergência de vozes com delicadeza e suportar histórias que são indelicadas e violentas nos impõe a pergunta: Como escutar? Jarid Arraes (2018) revela pistas de uma caixa mística sobre a mesa: "aproxime-se em silêncio depois do corpo lavado peça permissão. quem sabe sussurro grito ou canto quem sabe o encontro e a queda da máscara. as coisas pequenas me importam porque as grandiosas estão intactas" (p. 146).

Eram perceptíveis o esforço e a força visceral que as mães fizeram para contar o momento considerado por elas o mais doloroso de suas vidas, o assassinato de seus filhos. $O$ silêncio das mães sobre o assassinato dos seus filhos foi instaurado mediante muita violência. Romper com o silêncio significava reviver a violência, a raiva, o sofrimento, o medo e a revolta diante da injustiça. Assim, elas expressaram sentimentos ambivalentes ao relatar o que vivenciaram. No primeiro contato com Tereza, ela disse: "Quanto mais eu falar sobre essa covardia que esses policiais fazem com a gente, com os familiares, eles chegam, entram na favela e tiram a vida sem dar direito a pessoa responder na justiça se ela estiver errada ou não. Então, faço questão de falar sobre esse assunto" (Tereza, encontro, dezembro de 2018). A possibilidade de denúncia e de rom- 
pimento do silêncio mobilizou Tereza a falar. No entanto, outros tantos sentimentos foram estimulados.

No dia seguinte, após contar sua história, Tereza não conseguiu trabalhar. Procurou o centro de saúde, pois havia ficado indisposta durante a madrugada, com dor de cabeça e sem conseguir dormir. A corporificação da dor foi recorrente nas experiências das mães interlocutoras da pesquisa. Como Grada Kilomba (2008/2019) sublinha, a somatização no corpo é uma forma de proteção do sujeito diante da intensa dor, muitas vezes incomunicável, proveniente da experiência psicológica do racismo que ceifou a vida dos filhos e mutilou a das mães. Desse modo, durante um mês, o contato com Tereza foi feito para dar suporte em relação à saúde dela. Tereza voltou a tomar antidepressivo e foi afastada do trabalho. Como lidar com experiências traumáticas do racismo na construção do campo de pesquisa? Qual o limite da pesquisa diante do sofrimento?

Quando Tereza sinalizou que poderia continuar a contar sua história, marcamos um novo encontro. Contudo, era possível identificar no olhar dela a apreensão frente à probabilidade de que seus sentimentos dolorosos voltassem à tona. Ela chegou a perguntar se a gravação (ou seja, a nossa conversa) seria breve. Tereza ainda estava se restabelecendo e sinalizava a impossibilidade de continuar contando sua história. Sendo assim, decidimos não prosseguir. Foram cruciais o cuidado e o respeito com os tempos de fala e os tempos de silêncio. Os temposafetos são das mães, e não da pesquisa. Em cada encontro, as mães desenhavam os contornos da interação, apontando os limites que a dor e o luto impunham às suas falas. 0 imperativo é do cuidado, e não da fala. Os momentos de silêncio, portanto, não representam a ausência de voz. 0 silêncio é carregado de palavras de dor e de revolta, e "recolhe em si as vozes mudas caladas engasgadas na garganta" (Evaristo, 2009/2017, p. 25). A fala pausada, o olhar, as lágrimas, o tremor do corpo e o silêncio são partes constitutivas de uma cadeia de transmissão dos efeitos subjetivos do genocídio do negro na vida dessas mulheres. Assim, o rompimento do silêncio decorrente de violência traumática não pode ser pautado unicamente no desejo de investigação, sem estar ligado a estratégias de cuidados.

Das várias experiências atravessadas pelas categorias raça, gênero e nacionalidade, os relatos das estudantes haitianas revelam violências, desigualdades e opressões de várias ordens que também são silenciadoras. Desde a chegada ao Brasil, Judie e Michou se veem expostas a situações desagradáveis e violentas, que são nomeadas por elas como racismo, considerando a formação social haitiana que revela essas tensões, diferentemente da dinâmica revelada nos relatos das interlocutoras de alguns países africanos. De toda forma, tais violências 
retratam, além do racismo interpessoal cotidiano, fendas do racismo estrutural, já que o tratamento institucional oferecido a essas estudantes é diferente, desde a recepção.

Os efeitos da submissão às violências raciais simbólicas e concretas não foram nomeados pelas estudantes haitianas do lugar da saúde ou do adoecimento - as interlocutoras sequer utilizam esses termos em seus relatos -, mas poderiam mover-se nessas direções, sugerindo, inclusive, que existem outros tipos de enfrentamentos possíveis. Destacamos a percepção de Judie e Michou de que as dinâmicas e as relações de gênero no Haiti têm se modificado ao longo do tempo, como revelado também em suas próprias trajetórias, em alguma medida pioneiras em seus contextos locais, algo que está diretamente relacionado à própria organização política das mulheres do país (Civil, 2018), evidenciando formas de resistência. No entanto, uma série de negociações precisaram ser feitas para tornar a trajetória de se dedicar aos estudos uma trajetória possível, aproximando-se da reflexão da escritora e teórica chicana feminista Gloria Anzaldúa (1987/2005) de que, em algumas situações, as mulheres que ousam questionar alguns sistemas de ocupação do espaço público se sentem incompreendidas pelos seus.

Eram as vozes-mulheres que nos interessavam nessas pesquisas. Como escreve Conceição Evaristo (2009/2017), nos interessam a lembrança da voz das que já se foram, das bisavós nos porões do navio, das avós na obediência dos brancosdonos, das mães nas cozinhas alheias, a força das vozes de agora, de sangue e fome, e a esperança das vozes que virão, como vida e liberdade. Falar, escutar, escrever, pesquisar "sobre essas posições marginais evoca dor, decepção e raiva" (Kilomba, 2008/2019 p. 57). No caso de histórias que acionam sofrimento e instigam a nomeação da dor, foram os aportes teóricos insurgentes que nos orientaram na escuta de vozes sussurradas e quase inaudíveis e na elaboração de reflexões de cuidado nos campos de pesquisa. Um método narrativo que privilegia a história contada, a ser experimentada como vivência conectada, e não para a pura especulação científica. Portanto, há que ter cuidados.

\section{COMPROMISSOS ÉTICO-POLÍTICOS: PENSANDO A RELAÇÃO DE PESQUISA EM PSICOLOGIA}

Patricia Hill Collins (1990/2019) sistematizou posturas que são requeridas como compromissos ético-políticos de uma epistemologia feminista negra como forma de validação de conhecimento. Para essa autora, os contornos de uma epistemologia feminista negra fundamentam-se em quatro dimensões: a experiência como critério de significado; a conexão, e não a separação, como um com- 
ponente essencial; a ética do cuidar (como expressividade pessoal), as emoções e a empatia como elementos centrais; e a ética da responsabilidade pessoal.

Em vez de implicar essencialização, a produção de uma ciência que considera a experiência das mulheres um aporte imprescindível para teorização científica produz epistemologias a partir de posicionamentos sociais singulares de mulheres negras nas estruturas de poder (Collins, 1990/2019), que historicamente têm sido silenciadas e desautorizadas epistemicamente. Além disso, permite assumir a importância da subjetividade e da emoção na práxis científica, contrapondo-se à hegemonia da racionalidade e da neutralidade. É impossível desconsiderar todos os sentimentos que a produção de conhecimento mobiliza: medo, raiva, tristeza, insegurança, saudade, amor. Aliás, o próprio genocídio do negro, foco de uma das pesquisas aqui mencionadas, mobiliza muito ódio, e não é possível compreendê-lo desconsiderando sua função na produção de mortes negras. Portanto, é necessário borrar a barreira rígida estabelecida pela ciência ocidental hegemônica entre razão e emoção. Há muito mais aprendizado em suas fronteiras.

Para a construção dos campos de pesquisa foi necessário mergulhar no encontro com as mulheres, visando construir uma autêntica relação de alteridade. Tais campos reivindicaram a necessidade de romper com a concepção positivista que cinde a racionalidade da emoção, em que somente aquela é tida como fundamento do saber, impondo um distanciamento entre quem pesquisa e quem é pesquisada(o), na falaciosa ideia de neutralidade científica. Na contramão dessa concepção, as mulheres interlocutoras das pesquisas compõem, com seus saberes, a produção do conhecimento científico, sendo esses saberes transmitidos por meio dos relatos de suas experiências e das emoções que emanam a partir delas. Compreende-se, desse modo, que "nem a emoção e tampouco a ética são subordinadas à razão. Na verdade, emoção, ética e razão são usadas de forma interconectada, como componentes essenciais na busca pelo conhecimento" (Collins, 1990/2019, p. 425).

Nossas pesquisas foram construídas a partir do diálogo estabelecido entre mutheres negras. Duas pesquisadoras negras, sob orientação de duas pesquisadoras brancas, em diálogo com experiências de outras mulheres negras, costuraram significados da experiência da mulher na diáspora negra, contribuindo com teorizações sobre o genocídio do negro e a diáspora no Brasil. Como corpospolíticos (Bernardino-Costa et al., 2018), é importante também produzir análises em torno dos atravessamentos - raciais, sociais, de poder etc. - que envolvem toda(o)s as(0)s sujeita(o)s presentes nas dinâmicas de produção de conhecimento. 0 encontro de mulheres negras em nossas pesquisas aponta a possibilidade de partilhas comuns, mas não homogêneas, de experiências que ad- 
vêm de uma mesma sociedade alicerçada no racismo e no patriarcado. Mas justamente esses sistemas de opressão impõem barreiras e distanciamentos nessa partilha. A conexão entre mulheres não ocorre de modo automático, pois cada mulher carrega sua história, sua cicatriz (Lorde, 1984/2020) e seus traumas (Kilomba, 2008/2019).

$\mathrm{Na}$ busca por construir relações de escuta, uma carta de Lorde, endereçada à sua terapeuta, poderia servir de disparador para pensar a relação de pesquisa. É claro que, na pesquisa, a demanda está invertida, são as pesquisadoras que buscam o encontro "olhos nos olhos" (Lorde, 1984/2020). Interessante que esse é o próprio cerne da palavra "entre-vista", tão desgastada nas metodologias científicas da psicologia. Na carta à terapeuta, Audre Lorde (1984/2020), aqui tomada para pensar essa relação, remete o olhar nos olhos de outra mulher negra a uma genealogia de construção de relações e expectativas. Como já sinalizado, as histórias tomadas em análise nesta escrita foram produzidas em articulação com as mulheres no campo das pesquisas de mestrado desenvolvidas por duas mulheres negras, sob orientação de duas mulheres brancas ${ }^{5}$. Na carta, inclusive, Lorde (1984/2020, p. 202) diz: "Eu não sei com quem você faz supervisão, mas aposto que não é com outra mulher negra”, e já previa essa relação (no caso da terapia, pensando na posição de supervisão).

Para duas mulheres negras, iniciar uma relação de terapia ou análise significa começar uma jornada essencialmente insegura e desconhecida... significa escolher um caminho através das nossas semelhanças e diferenças, e também através das nossas histórias de desconfiança e desejo calculados (...) Então, esse território entre nós parece novo e assustador tanto quanto urgente, infestado de minas terrestres de nossas histórias raciais individuais que nenhuma de nós escolheu, mas das quais todas nós herdamos cicatrizes. E essas cicatrizes são específicas a cada uma de nós. Mas existe uma história que compartilhamos por sermos mulheres negras em um caldeirão machista e racista e isso significa que parte dessa jornada também é sua. (Lorde, 1984/2020, pp. 202-203)

No encontro de pesquisa, tanto nós, pesquisadoras, quanto as mulheres interlocutoras da pesquisa carregam bagagens que são ao mesmo tempo individuais e

${ }^{5}$ Esse tem sido um processo transformador da universidade, iniciado pela inserção das cotas para o acesso aos cursos de graduação em 2012 (Lei federal $n^{\circ}$ 12.711) e intensificado com cotas na pós-graduação e na docência. Em nosso contexto institucional, as cotas no Programa de Pós-Graduação da Psicologia foram garantidas somente em 2017, e apenas em 2020 foi realizado o primeiro concurso para docente com cota racial para o Departamento de Psicologia. 0 antropólogo brasileiro José Jorge de Carvalho (2020) ressalta a necessidade de garantir também cotas epistêmicas para quem antes figurava como objeto da ciência e depois passou a se consolidar como aprendiz, para que então possamos garantir também o lugar de produtores de conhecimento. 
históricas. O cuidado, a troca genuína, o amor entre mulheres negras (Lorde, 1984/2020), palavras tão estranhas e esvaziadas de significados na atualidade, sobretudo para a ciência, são tidas como potentes ferramentas epistemológicas negras de transformação individual e coletiva, bem como de ampliação da capacidade de compreensão do mundo e da práxis científica. Nessa perspectiva, a tríade reflexividade, posicionalidade e criticidade torna-se inerente ao fazer científico. Colocar em análise o lugar ocupado pelas pesquisadoras, assim como as lentes que utilizam para compreender a realidade social, é implicação necessária na mudança que se pretende revolucionária (Lorde, 1984/2020). Assim, torna-se possível identificar qual parte do opressor seguimos a carregar nas nossas próprias bagagens e compreender que, se falharmos em não reconhecer em outras mulheres negras a nossa face, estamos contribuindo não apenas com a opressão delas, mas também com as nossas (Lorde, 1984/2020).

Priorizamos a autoapresentação, na qual toda(o)s a(o)s interlocutora(e)s da pesquisa com estudantes haitianas elencaram seus próprios nomes, sendo alguns fictícios, outros não. Já na pesquisa com as mães, considerando a segurança delas, foi necessário um cuidado maior com relação a suas identificações e à apresentação de suas histórias. Excetuando Elizete, que utiliza seu próprio nome, as demais mães tiveram seus filhos assassinados pela ação da polícia e continuam sob a mira genocida do Estado. Os nomes das mães e de seus filhos foram substituídos pelo primeiro nome de personalidades negras que desafiaram e enfrentaram, em diferentes frentes de luta, a política de morte simbólica, social e física imposta ao povo negro: Luísa Mahin e Luís Gama, Tereza de Benguela e João Cândido, Maria Firmina dos Reis e Francisco José do Nascimento, Carolina Maria de Jesus e José do Patrocínio, Esperança Garcia e André Pinto Rebouças. Essa escolha busca dar visibilidade à luta histórica do povo negro em diáspora pela sobrevivência e sublinhar as resistências ao Estado genocida, tecidas anônima e diariamente pelas mulheres negras e pela juventude negra, nas favelas e nas periferias das cidades brasileiras.

Para nós, "esse ato de fala, de 'erguer a voz', sobretudo, em contextos de violência, não é um mero gesto de palavras vazias: é uma expressão de nossa transição de objeto para sujeito - a voz liberta" (hooks, 1981/2019, p. 39). É um movimento coletivo, e não de uma única voz. Isso implica responsabilidade ético-política das pesquisadoras que não finda com a conclusão da pesquisa, pois o compromisso que exige o feminismo negro não é apenas com uma diplomação individual, por mais que tenha sua importância. Tal responsabilidade reside, principalmente, em ancorar a produção do conhecimento em um projeto político de transformação social e de luta antirracista. 
Desse modo, aceitamos o convite de Anzaldúa (1981/2000, p. 235) para "evocar as realidades pessoais e sociais - não através da retórica, mas com sangue, pus e suor", de forma a não deixar a tinta coagular na caneta, tampouco mordaças abafarem nossas vozes. Escrevemos carregadas de dúvida: Como seguir com a escrita, enquanto ferramenta política, quando 80 tiros de fuzil atravessam os corpos dos nossos 6 ? Faz sentido escrever para espaços que, ainda em grande medida, não são acessados por muitas das mulheres que nos acompanharam nas pesquisas e em outros encontros não acadêmicos? Se nossas(o)s interlocutora(e)s nesta escrita são outra(o)s, apostamos na potência desses outros encontros. A possibilidade de escrever para outras monstras perigosas (Oliveira, 2017), que ousam ocupar o espaço acadêmico e reivindicar o lugar de cientistas. Ao escrever sobre mulheres negras na ciência psicológica, a psicóloga brasileira Tayane Lino (2019) aponta que:

A tarefa foi escrever para me transformar, me desprender e me dissociar de mim mesma, dos meus medos. Esta ação foi, essencialmente, a tentativa do começo de algo novo, sendo este o próprio exercício da liberdade. Assim, dentre as várias possibilidades de contribuir para a causa das mulheres na ciência, escolho a via da pesquisa feminista em Psicologia. (p. 56)

Inspiradas em Evaristo, entendemos que escrever para a casa grande - representada pela ciência hegemônica - só fará sentido se o fizermos não com contos para adormecer, mas com histórias que a desperte de seus sonos injustos. É nessa conexão que a relação se estabelece em pesquisas que não são descorporificadas e que buscam disputar espaços, somando-se a outras práticas científicas insurgentes, com o intuito de romper com o pacto hegemônico cientificista. Mesmo "se tornando a margem do saber legítimo e legitimado por tal comunidade, sendo por eles consideradas impróprias e inapropriáveis" (Lino, 2019, p. 56), nossas vozes são científicas. Há uma aposta de que essa escrita tenha utilidade, mesmo que não se saibam ainda os caminhos para transformar o caos em novos mundos.

Eu não sei como elas podem ajudar e iluminar sua vida e seu trabalho - só sei que podem. Às vezes tanto a bênção quanto a maldição da poeta é perceber sem conseguir organizar de imediato as percepções, e isso é mais um nome para o Caos. Mas é claro que é do Caos que nascem novos mundos. (Lorde, 1984/2020, p. 203)

${ }^{6}$ Evaldo dos Santos Rosa foi assassinado com 80 tiros de fuzil, disparados por oficiais do exército brasileiro enquanto ele dirigia seu carro, levando sua família a um chá de bebê, no dia 7 de abril de 2019. Luciano Macedo, catador de recicláveis, que estava próximo ao local, tentou ajudar Evaldo e também foi alvejado. 
Como pode ser observado, nossas escolhas ético-políticas não estão isentas de perigos, sendo necessário evidenciar, analisar e enfrentar os riscos encontrados no percurso de produção de conhecimento. Há riscos de que as próprias vozes sejam usadas como manutenção de posições de subalternidade. "Ouça. Os vethos caminhos indo embora e voltam fingindo mudança, mascarados como denúncia e lamento, mascarados como escolha, entre espelhos sôfregos que embaçam e distorcem a nós em definições fáceis" (Lorde, 2020, pos.1189).

Uma importante ressalva é feita pela escritora e feminista estadunidense bell hooks (1981/2019), atenta ao modo como a noção de força atribuída à mulher negra pode ser uma análise sedutora. Nessa abordagem, pesquisas produzem a romantização do sofrimento, quando reconhecem a vitimização e enfatizam o modo como as mulheres contornam o impacto da opressão. Podemos mencionar a história de Marli Pereira Soares, mulher negra, da periferia e brasileira, que lutou por justiça pelo assassinato do irmão, Paulo Pereira Soares, pela polícia em plena ditadura militar. Mesmo Marli narrando sinais de esgotamento psíquico, dizendo-se nervosa e esgotada tanto pelo luto devido à perda do irmão quanto pela revitimização provocada pela violência do Estado, ela era vista como uma mulher de força extrema, quase sobrenatural (Moreira et al., 2020). A ela não foi dado o direito ao luto, tampouco seu sofrimento era compreendido do ponto do cuidado.

Judie relatou que o primeiro semestre de seus estudos no Brasil foi muito doloroso, pois sentia-se invisível na sala de aula, o que se modificou no semestre seguinte, quando começou a falar e expor suas ideias com mais frequência. Esse movimento de visibilizar-se, que pode ser tomado como uma vitória individual ou uma superação do racismo nesse microcosmo da sala de aula, foi tomado em outros termos, especialmente quando combinado à experiência de outra(o)s estudantes em diáspora no Brasil e de outra(o)s estudantes negra(o)s brasileira(o)s, sendo lido como estratégia frágil em que se privatiza uma questão que é coletiva e política. Dessa forma, "ignoram a realidade de que ser forte diante da opressão não é o mesmo que superá-la, que resistência não deve ser confundida com transformação" (hooks, 1981/2019, p. 25).

A colonialidade também pode se expressar como extrativismo científico, em que as vozes são sequestradas como dados a serem coletados, produzindo a sensação de terra devastada. Antes de optar pelo Haiti como interlocutor central da pesquisa na categoria nacionalidade, foram feitas incursões em conversas com mulheres de países africanos. No entanto, um registro importante do campo ficou de fora nesse processo. A primeira consultora da pesquisa foi Michou, que indicou uma colega; ao abordá-la, ela relatou que não tinha interesse nenhum em participar de uma nova pesquisa, pois a última vez que isso ha- 
via ocorrido, não teve devolutiva ou não viu retorno direto de sua participação. Em outros termos, ela nos diz: qual a utilidade prática dessa participação ou em que isso muda ou contribui para as situações que estamos narrando com tanto sofrimento?

Essa pergunta remete a combinações acordadas e a compromissos éticopolíticos assumidos diretamente com as mulheres interlocutoras das pesquisas, além de interpelar sobre os desdobramentos das produções científicas. Os primeiros arranjos de respostas a essa pergunta podem produzir um certo nível de paralisia na movimentação em direção ao campo, tempo de recalcular a rota. Mas a relevância de perguntas como a colocada acima reside no convite (ou na convocação) para pensarmos sobre a ética do cuidado e da responsabilidade pessoal da(o) pesquisadora(o) em problematizar quais trocas são possíveis entre pesquisadora(e)s e interlocutora(e)s da pesquisa e como (e se) essa disputa pelo espaço acadêmico pode produzir ou impactar algum nível de transformação social.

Apostamos na produção de conhecimento que cria significados para todas as envolvidas no processo, sem deixar de reconhecer que ocupamos lugares sociais distintos nas possibilidades de troca/acordo/negociação. Acreditamos que, quando isso acontece de modo ético, respeitoso e responsável, tem um potencial transformador. Quando as mães ou as estudantes haitianas reconhecem que amplificar suas histórias, lutas e sofrimentos por outros meios, como o acadêmico, no primeiro caso, ou evidenciar o racismo genderizado, territorializado e enraizado no Brasil, no segundo caso, é importante para tensionar visões hegemônicas - tais como o genocídio do negro, a segurança pública e o deslocamento internacional -, tornam-se potentes ativos que funcionam como fagulhas a serem somadas a outras insurgências, que buscam dirimir desigualdades, combater opressões e afrontar violências epistêmicas.

\section{CONSIDERAÇÕES}

Sabemos que a psicologia tende a individualizar ou privatizar as subjetividades, distanciando indivíduo e sociedade (Lino, 2019), erigindo-se como disciplina da investigação da subjetividade por meio da patologização de certos corpos, contribuindo para a marginalização e consequente eliminação simbólica, social e física desses corpos.

Partimos da euforia contagiante da confusão evocada na ideia da quizumba armada, presente na epígrafe do texto "Racismo e sexismo na cultura brasileira", de Gonzalez (1984/2020, p. 75): "a negrada parecia que tava esperando por isso prá bagunçar tudo”. Buscamos, então, pelo canto das mulheres-pássaros en- 
gaioladas, que resistem à eliminação cantando por liberdade, que armam quizumba e que apontam outros possíveis caminhos teórico-metodológicos para a construção de pontes com experiências historicamente marginalizadas.

Certamente as perguntas elencadas ao longo deste artigo não encontram respostas fechadas, mas nos guiam e permanecem como reflexões epistemológicas, especialmente a questão central sobre como escutar, registrar e analisar as vozes de mulheres negras.

Michou deixa a seguinte mensagem para a(o)s colegas da universidade e para as pessoas da cidade que a recebem: "acho que eu diria pra dar mais abertura para nós em todas as instâncias. Se mostrar disponível pra nos ouvir, pra nos entender, porque temos muito a dizer, a explicar, a ensinar" (Michou, entrevista em grupo, dezembro de 2018). Maria, que perdeu seu filho Francisco e o pai dele pela violência policial, expressa sua indignação, que se encontra com a de outras mulheres negras cujo direito ao exercício da maternidade é institucionalmente negado: "Depois, eles mataram um menino de 14 anos. Uma vez eles mataram um outro, na época de Natal, no dia do Natal eles mataram o menino. Depois entraram na casa de um outro, mataram ele. E aí vai... Enquanto o povo não se movimentar a lista vai ficar assim..." (Maria, encontro, dezembro de 2018).

O convite de Michou e a denúncia de Maria interpelam a urgência de desnaturalizar as violências nos distintos espaços em que temos circulado e ocupado, violências que têm ocorrido historicamente e contra as quais a psicologia, como ciência e profissão, tem insurgido muito lentamente. Seguiremos quizumbando-a.

\section{REFERÊNCIAS}

Amorim, Rayanne C. S. \& Oliveira, Érika S. (2020). A escrita de Carolina Maria de Jesus como instrumento de intervenção política. Em Érika Oliveira, Marcos Mesquita \& Tatiana Souza (Orgs.), Feminismos, psicologias e resistências contemporâneas (pp.159178). Edufal.

Angelou, Maya (1969/2018). Eu sei por que o pássaro canta na gaiola. Tradução: Regiane Winarski. Astral Cultural.

Angelou, Maya (1978/2020). Maya Angelou: poesia completa. Tradução: Lubi Prates. Astral Cultural.

Anzaldúa, Gloria (1981/2000). Falando em línguas: uma carta para as mulheres escritoras do terceiro mundo. Revista Estudos Feministas, 8(1), 229-236. Tradução: Édna de Marco. Revisão: Claudia de Lima Costa e Simone Pereira Schmidt. http://dx.doi.org/10.1590/S0104-026X2005000300014

Anzaldúa, Gloria (1987/2005). La conciencia de la mestiza: rumo a uma nova consciência. Revista Estudos Feministas, 13(3), 704-719. https: / / doi.org/10.1590/S0104-026X2005000300015 
Arraes, Jarid (2018). Um buraco com meu nome. Ferina.

Bernardino-Costa, Joaze; Maldonado-Torres, Nelson \& Grosfoguel, Ramón (2018). Introdução. Em Decolonialidade e pensamento afrodiaspórico (pp.9-25). Autêntica Editora. (Coleção Cultura Negra e Identidades)

Carneiro, Aparecida Sueli (2005). A construção do outro como não ser como fundamento do ser.Tese de Doutorado publicada. Universidade de São Paulo.

Carvalho, José Jorge de (2020). Encontro de saberes e descolonização: para uma refundação étnica, racial e epistêmica das universidades brasileiras. Em Joaze Bernardino-Costa, Nelson Maldonado-Torres \& Ramón Grosfoguel (Rrgs.), Decolonialidade e pensamento afrodiaspórico (pp. 79-106). Autêntica.

Civil, Jude (2018). Dobras do tempo: a comunicação entre passado e presente a partir de experiências de imigração, racismo e desigualdades de gênero em relatos orais de haitianas em Belo Horizonte. Trabalho de Conclusão de Curso publicado. Universidade Federal de Minas Gerais.

Collins, Patricia Hill (1990/2019) Pensamento feminista negro: conhecimento, consciência e a política do empoderamento (Tradução: Jamille Pinheiro Dias). Boitempo.

Cunha, Vivane Martins (2019). Vestígios de histórias silenciadas: Vozes de mães sobre o genocídio negro. Dissertação de Mestrado em Psicologia não publicada. Universidade Federal de Minas Gerais.

Edwards, Brent Hayes (2017). Os usos da diáspora. Translatio, 13, 40-71.

Evaristo, Conceição (2009/2017). Poemas da recordação e outros movimentos. Malê.

Francisco, Camila Rodrigues (2019). Trajetórias em diáspora: a experiência de universitárias haitianas de Belo Horizonte. Dissertação de Mestrado em Psicologia não publicada. Universidade Federal de Minas Gerais.

Francisco, Camila Rodrigues \& Mayorga, Claudia (2020). Insurgências nas trajetórias em diáspora de universitárias haitianas em Belo Horizonte, Brasil. Gênero, 20(2), 5784. https://doi.org/10.22409/rg.v20i2.44569

Gonzalez, Lélia (1984/2020). Por um feminismo afro-latino-americano: ensaios, intervenções e diálogos (Organização: Flavia Rios e Márcia Lima). Editora Zahar.

hooks, bell (1981/2019). E eu não sou uma mulher?: mulheres negras e feminismo (Tradução: Bhuvi Libânio). Rosa dos Tempos.

Jesus, Carolina Maria de (1960). Quarto de Despejo: diário de uma favelada. Francisco Alves (Edição Popular).

Kilomba, Grada (2008/2019). Memórias da plantação: episódios de racismo cotidiano. Editora Cobogó.

Lima, Fátima (2020). Trauma, colonialidade e a sociogenia em Frantz Fanon: os estudos da subjetividade na encruzilhada. Arquivos Brasileiros de Psicologia, 72(spe), 8093. http://dx.doi.org/10.36482/1809-5267.arbp2020v72s1p.80-93

Lino, Tayane Rogeria (2019). Psicólogas, Cientistas e Feministas: a produção de si e de uma ciência psicológica posicionada. Tese de Doutorado publicada. Universidade Federal de Minas Gerais, Belo Horizonte.

Lorde, Audre (1984/2020). Irmã outsider. Grupo Autêntica. 
Lorde, Audre (2020). Entre nós mesmas: Poemas reunidos (Tradução: Tatiana Nascimento e Valéria Lima). Editora Bazar do Tempo. [ebook].

Luedji, Luna (2017). Asas. Em Um corpo no mundo [CD]. São Paulo: YB Music.

Mães de Maio (2011). Do luto à luta. Nós por nós. Movimento Mães de Maio.

Mbembe, Achille (2013/2018). Crítica da Razão Negra. n-1 edições.

Moreira, Lisandra Espíndula; Cunha, Vivane Martins \& Francisco, Rafael Porto (2020). Genocídio, luto e resistências: 40 anos da voz de Marli. Em Érika Oliveira; Marcos Mesquita \& Tatiana Souza (Orgs.), Feminismos, psicologias e resistências contemporâneas. (pp. 200-223). Edufal.

Oliveira, Érika Cecília Soares (2017). Uma "monstra perigosa": Pistas de Carolina Maria de Jesus para a intervenção psicossocial. Estudos de Psicologia (Natal), 22(4), 378388. http://doi.org/10.22491/1678-4669.20170039

Oliveira, Érika Cecília Soares (2020a). A docência como uma performance feminista. Pesquisas e Práticas Psicossociais, 15(3), 1-13. http://www.seer.ufsj.edu.br/index.php/revista_ppp/article/view/4021

Oliveira, Érika Cecília Soares (2020b). O Pensamento de Fronteira de Carolina Maria de Jesus. Psicologia: Ciência e Profissão, 40, e212106. https://doi.org/10.1590/19823703003212106

Soares, Elza (2015). Mulher do fim do mundo [CD] [Rômulo Fróes e Alice Coutinho]. Em A mulher do fim do mundo. São Paulo: Gravadora Circus.

\section{VIVANE MARTINS CUNHA}

Graduada em Psicologia (UFMG/2012). Especialista em Saúde da Criança e do Adolescente (UFMG/2016). Mestrado em Psicologia Social (UFMG/2019). Doutorado em andamento pelo Programa de Pós-graduação em Psicologia da UFMG (2020-2024). cunha.vivane@gmail.com http: / / lattes.cnpq.br/4855400618972025 https://orcid.org/0000-0002-5125-2529

\section{CAMILA RODRIGUES FRANCISCO}

Graduada em Psicologia (UFMT/2016). Mestrado em Psicologia Social (UFMG/2019). Doutorado em andamento pelo Programa de Pós-graduação em Psicologia Social da PUC-SP (2021-2025). cfmilarodrigues@gmail.com http: / / lattes.cnpq.br/5510005469033375 https://orcid.org/0000-0002-9867-9095 


\section{LISANDRA ESPÍNDULA MOREIRA}

Professora do Programa de Pós-Graduação em Psicologia da Universidade Federal de Minas Gerais (UFMG). Doutora em Psicologia (UFSC/2013). Mestre em Psicologia Social e Institucional (UFRGS/2008) e Graduada em Psicologia (UFRGS/2003).

http: / / lattes.cnpq.br/9536102634454549

https://orcid.org/0000-0001-9356-3416

lisandra.ufmg@gmail.com

\section{FINANCIAMENTO}

0 presente trabalho foi realizado com apoio da Coordenação de Aperfeiçoamento de Pessoal de Nível Superior - Brasil (CAPES) - Código de Financiamento 001.

\section{FORMATO DE CITACIÓN}

Cunha, Vivane Martins; Francisco, Camila Rodrigues \& Moreira, Lisandra Espíndula (2021). A produção do conhecimento em psicologia a partir das experiências de mulheres negras diaspóricas. Aspectos teórico-metodológicos. Quaderns de Psicologia, 23(3), e1771. https://doi.org/10.5565/rev/qpsicologia.1771

HISTORIA EDITORIAL

Recibido: 30-01-2021

$1^{a}$ revisión: 12-04-2021

Aceptado: 26-04-2021

Publicado: 25-01-2022 